\title{
The relationship of the development of motor skills and socioeconomic status of family with BMI of children with autism disorder
}

\author{
Ali Akbar Barrodi sedehi ${ }^{1 \mathrm{ABCDE}}$, Abdollah Ghasemi ${ }^{2 \mathrm{ABCD}}$, Ali Kashi ${ }^{\mathrm{ABCD}}$, Elham Azimzadeh ${ }^{4 \mathrm{ABCD}}$ \\ 1,2 Department of Physical Education, Science and Research Branch, Islamic Azad University, Tehran, Iran \\ ${ }^{3}$ Sport Science Research Institute of Iran (SSRI), Tehran, Iran \\ ${ }^{4}$ Faculty of Sport Sciences, Shahid Beheshti University, Tehran, Iran
}

\begin{abstract}
Purpose:

This study aims to examine the relationship between the development of motor skills and the socioeconomic status of families with body mass index (BMI) of children with autism disorder.

Material: $\quad$ To this end, 68 children with autism at the age range of 6-13 years old were selected for the study. Their parents completed Family Socioeconomic Status Questionnaire. The motor skills level of children was measured by the Movement Assessment Battery for Children (MABC). The height and weight of children were measured to calculate their BMI. The results of the Pearson correlation test showed that there is a significant and negative relationship between the development of motor skills and the socioeconomic status of families with BMI of children with autism.

Results: $\quad$ The results of the linear regression test also indicated that motor development and family socioeconomic status are predictors of $\mathrm{BMI}$ in people with autism $(\mathrm{P}<0.05)$.

Conclusions: It is concluded that the socioeconomic status of the family and the motor development of children with autism are the determinants of their overweight and obesity and these factors should be considered in the interventions for children and families.

Keywords: gross motor skill, fine motor skill, BMI
\end{abstract}

\section{Introduction}

Overweight and obesity have become one of the global challenges of the current era. While the global prevalence of overweight and obesity in children has been reported as $6.7 \%$ [1], some reports indicate the higher prevalence of obesity in mentally retarded people [2] and those with developmental disorders [3]. This is a concern because it exacerbates the problems of these people. Autism prevalence in children with autism is $22.2 \%$. They are $41.1 \%$ more likely to suffer obesity [4].

Overweight and obesity in children are usually related to medical (type II diabetics) or mental (depression) comorbidities $[5,6]$. Consequently, the increase in weight and obesity in children with autism can harm their quality of life, increase the costs, and lead to more exhaustion of their parents [7]. In the US, the cost of living of people suffering from autism is 1.4 to 2.4 million dollars during the lifespan. To this end, it is important to find some solutions to these problems and prevent them.

Physical activity, sleep, motor skills levels and sedentary behaviors are among the important and effective factors of childhood obesity [8]. The previous studies showed that people with autism have basic problems in motor skills, in addition to problems in speaking, social communication and eye contact [9, 10]. Barrodi et.al indicated that children with autism have a lowperformance level in motor skills. It is worthy to mention that the failure in motor skills has been seen in these children at low ages and before one-year-old [11]. This

(c) Ali Akbar Barrodi sedehi, Abdollah Ghasemi, Ali Kashi,

Elham Azimzadeh, 2021

doi:10.15561/26649837.2021.0303 leads to the assumption that maybe one of the reasons for increasing BMI is the failure in motor skills and lack of enough physical activity in these people. Studies about healthy people have shown that there is a significant relationship between BMI and motor skills. For example, D'Hondt et.al [5] showed that obscene and overweight children have more weak performance than their peers. Di Mister et.al [6] indicated that children with lower motor skill levels show more tendency to increase in weight and easily become obscene.

On the other hand, one of the effective factors on the BMI of children is the socio-economic status of their families [8]. In a study in South Africa, it was shown that children from different socio-economic classes require the prescription of physical activity [7] while the previous studies in countries with higher incomes confirmed the opposite $[12,13]$. There is not yet a comprehensive study to determine the relationship between socio-economic status and motor skills level with BMI, despite the necessity of controlling weight in people with autism disorder. As a result, the current study seeks to answer that is there a relationship between socio-economic status and motor skill levels and BMI? Can we predict BMI by using these variables?

\section{Material and Methods}

\section{Participants}

In this study, 68 children with autism in the age range of 3-16 years old (mean=8.27, $\mathrm{SD}=3.20$ ) were selected and studied by referring to education and rehabilitation centers for children with autism in Mashhad city. 
The inclusion criteria were suffering autism disorder confirmed by psychiatrists, lack of comorbidities like hyperactivity, mental retardation, musculoskeletal problems, cardiovascular disease, and epilepsy. All parents signed the informed consent forms after becoming aware of the study procedure.

Research Design.

Tools

Movement Assessment Battery for Children-Second Edition (MABC-2)

It is one of the most widely used and common tests for measurement and diagnosis of motor disorders in children that measures fine motor skills, gross motor skills, and motor proficiency of an individual [14]. It has a defined norm and it is used for 3-17years old age range. This test is the result of two decades of research by Henderson et.al [15] and has three age ranges: 3-6 years old, 7-10 years old, and 11-17 years old. This battery consists of a checklist and descriptive instruction to diagnose children with motor coordination disorder. This test includes a set of gross and fine motor tasks. Tasks divide into three sections: 1) manual dexterity skill (including skills like placing pegs, threading and drawing a maze), 2) aiming and catching (catching and throwing beanbag), and 3) balance skill (one-leg balance, walking heels raised, hopping). The total test time is about 20 to 40 minutes [14]. This test has been validated in Iran by Akbaripour et.al [16] and its Cronbach alpha is 0.843 .

\section{Family Socioeconomic Status Questionnaire}

A socioeconomic status questionnaire was used to measure the socioeconomic status of children. This questionnaire has four items: income, economic class, education, and housing. It consists of 6 demographic questions and 5 main questions. The measurement scale for questions in this questionnaire was the five-point scale and the scoring is from very low $=1$ to very high $=5$.

Face and content validities of the given questionnaire confirmed by 12 experts. Its reliability with Cronbach alpha was 0.83 .

Procedure

After coordination with centers and parents of the participants, the selected children were examined by motor behavior experts by MABC-2. This test was conducted in a calm setting by the cooperation of the teachers in the education center of children to avoid the effects of a new setting on the performance of the participants. Parents and teachers responded to the socioeconomic status questionnaire. The raw scores of both tests converted to standard scores and related coefficients by experts, using the norms and related instructions and applied in the statistical analysis.

\section{Statistical Analysis}

Pearson correlation test was used to determine the relationship between the variables of the study. Linear regression was also used to determine the predictability of subjects' BMI scores from their motor skill scores and socioeconomic status. All statistical tests were conducted by SPSS software Version 23 in $\alpha=0.05$ statistical level.

\section{Results}

Table 1 indicates the demographic information of the subjects.

The results of this study showed that from among participants in this study, $22.9 \%$ suffer low weight and $31.4 \%$ suffer overweight. $54.7 \%$ have normal weight. The information obtained from the socioeconomic status of families shows that $28.6 \%$ of them are in a low class, $68.6 \%$ are in the middle class and only $2.9 \%$ are in high class. $92.9 \%$ of children were in a low class, $2.9 \%$ in the middle class, and $4.3 \%$ in high class in terms of motor development.

Results of the Pearson correlation test showed that there is a negative significant relationship between families' socioeconomic status and BMI in children with autism $(\mathrm{r}=0.781, \mathrm{p}=0.001)$. There is also a negative significant between fine motor skills ( $r=0.858, \mathrm{p}=0.001)$, gross motor skill $(\mathrm{r}=0.781, \mathrm{p}=0.001)$ and motor proficiency $(\mathrm{r}=0.866$, $\mathrm{p}=0.001)$.

Multiple linear regression was used to determine the likelihood of predicting autism severity by motor skills that the results are presented in Table 2.

Table 1. Demographic information of subjects

\begin{tabular}{lllll}
\hline Variable & Minimum & Maximum & Standard deviation & Mean \\
\hline Age (year) & 3.10 & 16.80 & 3.20 & 8.27 \\
Height $(\mathrm{m})$ & 1.02 & 1.65 & 0.16 & 1.26 \\
Weight $(\mathrm{kg})$ & 1.76 & 140 & 20.56 & 41.07 \\
BMI & 15.35 & 75.46 & 9.82 & 25 \\
Socioeconomic status & 6 & 21 & 3.47 & 12.42 \\
Autism severity & 66 & 151 & 17.65 & 96.61 \\
Fine skill & 1 & 9 & 1.96 & 3.41 \\
Gross skill & 2 & 22 & 4.86 & 6.67 \\
Motor proficiency & 6 & 66.5 & 15.18 & 28.72 \\
\hline
\end{tabular}


Table 2. Regression analysis for predicting autism severity from motor skills

\begin{tabular}{lllllllll}
\hline Model & Sum of squares & $\begin{array}{l}\text { Degree of } \\
\text { freedom }\end{array}$ & $\begin{array}{l}\text { Mean } \\
\text { squares }\end{array}$ & $\mathbf{F}$ & $\mathbf{R}$ & $\mathbf{R}^{\mathbf{2}}$ & $\mathbf{R}_{\text {adj }}$ & Sig. \\
\hline Regression & 1877.63 & 4 & 469.40 & 133.22 & 0.944 & 0.891 & 0.885 & 0.001 \\
Remained & 229.02 & 65 & 3.52 & & & & & \\
Total & 2106.65 & 69 & & & & & \\
\hline
\end{tabular}

Table 3. Standard and non-standard coefficients and t-statistics inserted in the regression model

\begin{tabular}{lllll}
\hline \multirow{2}{*}{ Predictor variable } & \multicolumn{2}{l}{ Regression coefficients } & t-statistic & Sig. \\
\cline { 2 - 4 } & B & Beta & & 12.66 \\
Fixed value & 28.94 & & 0.001 \\
Socioeconomic level & 0.414 & 0.261 & 3.54 & 0.001 \\
Fine motor skill & -2.86 & -1.01 & -5.67 & 0.001 \\
Gross motor skill & 1.69 & 1.49 & 7.49 & 0.001 \\
Motor proficiency & -0.411 & -1.12 & -4.65 & 0.001 \\
\hline
\end{tabular}

As seen in Table 3, the regression model is significant. $\mathrm{R}^{2}$ adj also shows that fine motor skills, gross motor skills, and motor proficient subscales can predict BMI up to $88 \%$. Then, it was observed that the socioeconomic level, fine motor skill, gross motor skill, and motor proficiency can predict the BMI of participants.

The results obtained in table 3 indicate that socioeconomic level with regression (0.261), fine motor skill (-1.01), gross motor skill (1.49), and motor proficiency (1.12) are capable of predicting BMI of participants. Indeed, this coefficient indicates that by increasing the predictor factors, the BMI of participants reduces.

\section{Discussion}

This study aimed to examine the relationship between the socioeconomic status of the family and the motor proficiency of BMI in children with autism. The obtained results indicated that about one-third of children with autism suffer overweight and obesity. In other words, the prevalence of obesity in these children is high. These results are consistent with the results of previous studies $[1,3,4]$. Memari et.al [3] showed that $13.3 \%$ of people participating in their study have overweight, $11.5 \%$ were obscene and $15.9 \%$ suffered hyperadiposis. Another part of the results of this study indicated that children with autism are very weak in motor proficiency. These results were also in line with previous findings [9, 10, 17]. Bricout et.al [18] showed that people with autism are different from the control group in motor skills like handicrafts and rolling the ball. It should be noted that children with autism are different from healthy children in motivations and their performance will be weak if they have not enough motivation [19].

The main part of the results of this study emphasizes the relationship between the socioeconomic status of the family and motor proficiency with BMI. The results of this study showed that there is a positive and significant relationship between family socioeconomic status and BMI. This means that by increasing the social welfare of the family, we witness overweight and obesity in children with autism. These results are in line with the results obtained for healthy people. As previous studies have shown, the modern lifestyle and increase the sedentary behavior have increased the risk of overweight and obesity in children. Besides, the results of this study confirm the results of previous studies in western countries that education of parents has an inverse relationship with overweight and obesity in children [20, 21]. The socioeconomic status of the family includes the education and income of the family. It seems that families with higher socioeconomic levels have higher educations. This will lead to paying more attention to the motor activities and motor interventions for the children and these parents have somehow used sport and physical activity to cope with the overweight and obesity of their children. They have also taken some steps toward healthy nutrition due to their higher education level because there is a direct relationship between nutrition and physical activity with BMI. In other words, unhealthy and highcalorie diet leads to overweight and obesity in children $[4,21]$. It is also likely that families with lower income use medications instead of motor interventions and sports classes because the medications are covered by insurance and they pay less cost. Using medications is accompanied by complications like overweight and obesity in children with autism [3]. As a result, it is suggested that the insurance-related bodies and supporting organizations provide sport and motor rehabilitation services insurance for families with autistic children.

The other parts of the results of this study showed that there is a significant relationship between motor skills level of children with autism and their BMI. These results confirm the results of the previous section because as said the low-income level of family prevents them to provide motor interventions for their children. Many of them try to spend their medical costs for the required interventions for their children such as speech therapy and mental occupational therapy and they neglect the importance of developing motor skills [9, 19]. Failure in motor skills in children, especially children with autism, can isolate and limit them [2]. This failure can lead them toward sedentary 
behavior that exacerbates their overweight and obesity $[2,19,22]$. Gross motor skills consist of skills such as running, throwing, catching, hopping, and trotting. These motor movements are the basis for a large number of games and sports activities. Enough development of gross motor skills will provide more motivation to participate in physical activity and the family will also show more tendency to use motor interventions and sport [19]. If the gross motor skill has done continuously and in the longterm, it will increase the calorie consumption and prevent obesity because it involves the large muscles of the body.

\section{Conclusion}

Regarding the results of this study, it can be concluded that the socioeconomic status of families with autistic children is a very important and effective factor for their BMI because it determines their lifestyles. This lifestyle will show them to either follow the medical solutions and medications or active lifestyle and physical interventions and sport.

\section{Conflict of interest}

Authors declare no conflict of interest.

\section{References}

1. DeOnis M,BlössnerM,BorghiE. Globalprevalence and trends of overweight and obesity among preschool children. The American Journal of Clinical Nutrition. 2010;92(5):1257-64. https://doi.org/10.3945/ajen.2010.29786

2. Sulton K, Jajat J. Relationship between Gross Motor Skills and Body Mass Index of Children with Intellectual Disability. Proceedings of the 3rd International Conference on Sport Science, Health, and Physical Education (ICSSHPE 2018), Bandung, Indonesia: Atlantis Press; 2019. https://doi.org/10.2991/icsshpe-18.2019.60

3. Memari AH, Kordi R, Ziaee V, Mirfazeli FS, Setoodeh MS. WeightstatusinIranianchildrenwithautismspectrumdisorders: Investigation of underweight, overweight and obesity. Research in Autism Spectrum Disorders. 2012;6(1):234-9. https://doi.org/10.1016/j.rasd.2011.05.004

4. Kahathuduwa CN, West BD, Blume J, Dharavath N, Moustaid-Moussa N, Mastergeorge A. The risk of overweight and obesity in children with autism spectrum disorders: A systematic review and metaanalysis. Obesity Reviews. 2019;20(12):1667-79. https://doi.org/10.1111/obr.12933

5. D'Hondt E, Deforche B, De Bourdeaudhuij I, Lenoir M. Childhood obesity affects fine motor skill performance under different postural constraints. Neuroscience Letters. 2008;440(1):72-5. https://doi.org/10.1016/j.neulet.2008.05.056

6. De Meester A, Stodden D, Brian A, True L, Cardon G, Tallir I, et al. Associations among elementary school children's actual motor competence, perceived motor competence, physical activity and BMI: A crosssectional study. PloS One. 2016;11(10): 0164600. https://doi.org/10.1371/journal.pone.0164600

7. Draper CE, Tomaz SA, Stone M, Hinkley T, Jones RA, Louw J, et al. Developing intervention strategies to optimise body composition in early childhood in South Africa. BioMed Research International. 2017;2017. https://doi.org/10.1155/2017/5283457

8. Tomaz SA, Prioreschi A, Watson ED, McVeigh JA, Rae DE, Jones RA, et al. Body mass index, physical activity, sedentary behavior, sleep, and gross motor skill proficiency in preschool children from a low-to middle-income urban setting. Journal of Physical Activity and Health. 2019;16(7):525-32. https://doi.org/10.1123/jpah.2018-0133

9. Ament K, Mejia A, Buhlman R, Erklin S, Caffo B, Mostofsky $\mathrm{S}$, et al. Evidence for specificity of motor impairments in catching and balance in children with autism. Journal of Autism and Developmental Disorders. 2015;45(3):742-51. https://doi.org/10.1007/s10803-014-2229-0

10.Fournier KA, Hass CJ, Naik SK, Lodha N, Cauraugh
JH. Motor coordination in autism spectrum disorders: a synthesis and meta-analysis. Journal of Autism and Developmental Disorders. 2010;40(10):1227-40. https://doi.org/10.1007/s10803-010-0981-3

11.Arabameri E, Sotoodeh MS. Early developmental delay in children with autism: a study from a developing country. Infant Behavior and Development. 2015;39:118-23. https://doi.org/10.1016/j.infbeh.2015.02.017

12.Hesketh KR, McMinn AM, Ekelund U, Sharp SJ, Collings PJ, HarveyNC, etal.Objectivelymeasuredphysicalactivityinfouryear-old British children: a cross-sectional analysis of activity patterns segmented across the day. International Journal of Behavioral Nutrition and Physical Activity. 2014;11(1):1. https://doi.org/10.1186/1479-5868-11-1

13.Chaput J-P, Colley RC, Aubert S, Carson V, Janssen I, Roberts KC, et al. Proportion of preschool-aged children meeting the Canadian 24-Hour Movement Guidelines and associations with adiposity: results from the Canadian Health Measures Survey. BMC Public Health. 2017;17(5):147-54. https://doi.org/10.1186/s12889-017-4854-y

14.Brown T, Lalor A. The movement assessment battery for children-second edition (MABC-2): a review and critique. Physical \& Occupational Therapy in Pediatrics. 2009;29(1):86-103. https://doi.org/10.1080/01942630802574908

15.Henderson SE, Sugden DA, Barnett AL. Movement Assessment Battery for Children-2. second edition (Movement ABC-2). London: The Psychological Corporation. 2007.

16.Akbaripour R, Daneshfar A, Shojaei M. Reliability of the Movement Assessment Battery for Children-(MABC-2) in childrenaged7-10yearsinTehran.RehabMed.2018;7(4):90-6. https://doi.org/10.22037/jrm.2018.111121.1776

17.Colombo-DougovitoAM, Reeve RE. Exploring the interaction of motor and social skills with autism severity using the SFARI dataset. Perceptual and Motor Skills. 2017;124(2):413-24. https://doi.org/10.1177/0031512516689198

18. Bricout V-A, Pace M, Dumortier L, Miganeh S, Mahistre Y, Guinot M. Motor Capacities in Boys with High Functioning Autism: Which Evaluations to Choose? Journal of Clinical Medicine. 2019;8(10):1521. https://doi.org/10.3390/jcm8101521

19.Case L, Schram B, Yun J. Motivating Children with Autism Spectrum Disorder in Gross Motor-skill Assessments. Journal of PhysicalEducation, Recreation \& Dance. 2019;90(4):32-8. https://doi.org/10.1080/07303084.2019.1568933

20.Shrewsbury V, Wardle J. Socioeconomic status and adiposity in childhood: a systematic review of crosssectional studies 1990-2005. Obesity. 2008;16(2):275-84. https://doi.org/10.1038/oby.2007.35

21.Bammann K, Gwozdz W, Lanfer A, Barba G, De Henauw 
S, Eiben G, et al. Socioeconomic factors and childhood overweight in Europe: results from the multi-centre IDEFICS study. Pediatric Obesity. 2013;8(1):1-12. https://doi.org/10.1111/j.2047-6310.2012.00075.x
22.Holloway JM, Long TM, Biasini F. Relationships Between Gross Motor Skills and Social Function in Young Boys With Autism Spectrum Disorder. Pediatric Physical Therapy, 2018:1. https://doi.org/10.1097/PEP.0000000000000505

\section{Information about the authors:}

Ali Akbar Barrodi sedehi; Ph.D Student; https://orcid.org/0000-0002-2464-9264; Barrodi_akbar@yahoo.com; Department of Physical Education, Science and Research Branch, Islamic Azad University; Tehran, Iran.

Abdollah Ghasemi; (Corresponding author); Assistant Professor; https://orcid.org/0000-0001-7113-6894; ghasemi_abdolla@yahoo.com; Department of Physical Education, Science and Research Branch, Islamic Azad University; Tehran, Iran.

Ali Kashi; Associate professor; https://orcid.org/0000-0003-1125-9125; ssrc.kashi@gmail.com; Sport Science Research Institute of Iran (SSRI; Tehran, Iran.

Elham Azimzadeh; Assistant Professor; https://orcid.org/0000-0001-9838-0117; e_azimzadeh@sbu.ac.ir; Faculty of Sport Sciences, Shahid Beheshti University; Tehran, Iran.

Cite this article as:

Barrodi sedehi AA, Ghasemi A, Kashi A, Azimzadeh E. The relationship of the development of motor skills and socioeconomic status of family with BMI of children with autism disorder. Pedagogy of Physical Culture and Sports, 2021;25(3):160-164. https://doi.org/10.15561/26649837.2021.0303

This is an Open Access article distributed under the terms of the Creative Commons Attribution License, which permits unrestricted use, distribution, and reproduction in any medium, provided the original work is properly cited (http://creativecommons.org/licenses/by/4.0/deed.en).

Received: 15.12 .2020

Accepted: 22.01.2021; Published: 30.06.2021 